\title{
Pilot-scale production of alkali activated concretes for marine engineering application
}

\author{
Luqian Weng ${ }^{1, a}$, Hailin Cao ${ }^{1, b}$, Shaobin $\mathrm{Li}^{1, \mathrm{c}}$, Krivenko Palvo ${ }^{2, \mathrm{~d}}$ \\ ${ }^{1}$ Advanced Materials Research Institute, Shenzhen Academy of Aerospace Technology, \\ Shenzhen, P.R.China \\ ${ }^{2}$ V.D.Glukhovsky Scentific Research Institute for Binders and Materials, Kiev National University of \\ Civil Engineering and Architecture, Kiev, Ukraine \\ aleeweng@126.com, ${ }^{\mathrm{a}}$ caohl@hit.edu.cn, ${ }^{\mathrm{C}}$ lishaobin245@163.com, ${ }^{\mathrm{d}}$ pavlo.kryvenko@gmail.com
}

Keywords: alkali activated concretes, pilot production, curing conditions.

Abstract. Alkali activated concretes possess the significant advantage over the traditional cements on their low footprint. To test the application possibilities of alkali activated concretes, a pilot-scale production of these concretes for marine engineering application was performed at the precast concrete manufacturing factory. Three pilot-scale production batches of slabs, two of which have been subjected to curing at $\mathrm{t}=20-30^{\circ} \mathrm{C}$ and one batch, which hardened in the ambient conditions (low temperatures) have been manufactured. This allowed to confirm a possibility and efficiency of two technological solutions/approaches to the manufacture of the concrete products from the alkali activated cements.

\section{Introduction}

Alkali metal compounds were excluded from traditional hydraulic cement components due to their high solubility. At the same time, studies held in order to reveal reasons of excellent durability of ancient cementitious materials in combination with data collected on stability and composition of natural mineral formations testified that this postulate was not correct. According to the data reported in [1-7], a reason of excellent durability is a considerably greater content of alkali metal compounds of ancient cements compared to contemporary Portland cement matrix. To test the application possibilities of alkali activated concretes, a pilot-scale production of the alkali activated cement (AAC) concretes for marine engineering application was performed at the precast concrete manufacturing factory in the city of Binzhou, P.R.China. Considering that the AAC concrete products might be manufactured at ambient temperatures of $10-15^{\circ} \mathrm{C}$, what generally required for the concrete mix design at the normal temperature about $20-22^{\circ} \mathrm{C}$ would be adjusted or re-designed in order to accelerate strength gain at the initial period. Therefore, the comparative tests aimed to reveal the influence of conditions of hardening on their quality have been performed, these were: at $\mathrm{t}=5-12^{\circ} \mathrm{C}$, $\mathrm{RH}=35 \%$ and $\mathrm{at} \mathrm{t}=25-30^{\circ} \mathrm{C}, \mathrm{RH}=100 \%$.

\section{Experimental}

The AAC concrete compositions under study are shown in Table 1. After manufacture one portion of the AAC concrete specimens were placed into a special chamber to provide a cure regime with $\mathrm{RH}=100 \%$, whereas the second portion of the AAC concrete specimens was covered with a plastic sheet material and allowed for hardening in ambient conditions $\left(\mathrm{t}=5-12{ }^{\circ} \mathrm{C}, \mathrm{RH}=35 \%\right)$. 
Table 1 AAC concrete compositions

\begin{tabular}{|c|c|c|c|c|}
\hline \multirow{2}{*}{ Concrete ingredients } & \multicolumn{4}{|c|}{ Concrete composition, $\mathrm{kg} / \mathrm{m}^{3}$} \\
\cline { 2 - 5 } & \multicolumn{4}{|c|}{ Marking } \\
\cline { 2 - 5 } & $\mathrm{B}-20-\mathrm{K}$ & $\mathrm{B}-20-\mathrm{H}$ & $\mathrm{B}-40-\mathrm{K}$ & $\mathrm{B}-40-\mathrm{H}$ \\
\hline Slag & 255.0 & 249.0 & 340.0 & 332.0 \\
\hline Mineral admixture & 15.0 & 15.0 & 20.0 & 20.0 \\
\hline Activator 1 & 18.0 & 24.0 & 24.0 & 32.0 \\
\hline Activator 2 & 12.0 & 12.0 & 16.0 & 16.0 \\
\hline Water reducer 1 & 1.5 .0 & 1.5 & 2.0 & 0.6 \\
\hline Water reducer 2 & 0.45 & 0.45 & 0.6 & 670.0 \\
\hline Fine aggregate & 780.0 & 750.0 & 648.0 & 1160.0 \\
\hline Coarse aggregate & 1200.0 & 1150.0 & 1202.0 & 0.35 \\
\hline W/C & 0.363 & 0.37 & 0.46 & \\
\hline
\end{tabular}

After the AAC concrete specimens were manufactured in one day, a possibility of de-shuttering was studied. After de-shuttering a portion of the AAC concrete specimens were covered with a plastic sheet material for further hardening and strength gain, the rest of the specimens were allowed to harden uncovered. According to the experimental results, a pilot-scale batch concrete with the composition B-20-H was manufactured, and was placed into the chamber for curing at temperature between $25-30^{\circ} \mathrm{C}$ and $\mathrm{RH}=100 \%$. On the next day the slabs were de-shuttered.

To increase the concrete early strength cured at ambient temperature, the works on producing the AAC concretes with early strength without the additive of ordinary portland cement (OPC) and with a low quantity of the OPC additive (2\%) in the AAC in the conditions of low temperatures with activator 3 and 4 have been performed. The AAC concrete compositions under study are given in Table 2. The AAC concrete specimens were covered with a plastic sheet material and allowed to harden in ambient conditions $\left(\mathrm{t}=6-14^{\circ} \mathrm{C}\right.$ and $\left.\mathrm{RH}=30-35 \%\right)$.

Table 2 AAC concrete compositions

\begin{tabular}{|c|c|c|c|}
\hline \multirow{2}{*}{ Concrete ingredients } & \multicolumn{3}{|c|}{ Concrete composition, $\mathrm{kg} / \mathrm{m}^{3}$} \\
\cline { 2 - 4 } & B-20-H-I & B-20-H-II & B-20-H-III \\
\cline { 2 - 4 } Slag & 258.0 & 252.0 & 246.0 \\
\hline Mineral admixture & - & - & 6.0 \\
\hline Activator 1 & 30.0 & 36.0 & 36.0 \\
\hline Activator 2 & 12.0 & 12.0 & 12.0 \\
\hline Water reducer 1 & 1.5 & 1.5 & 1.5 \\
\hline Water reducer 2 & 0.45 & 0.45 & 0.45 \\
\hline Fine aggregate & 750.0 & 750.0 & 750.0 \\
\hline Coarse aggregate & 1150.0 & 1150.0 & 1150.0 \\
\hline W/C & 0.347 & 0.32 & 0.33 \\
\hline
\end{tabular}

Furtheermore, in order to satisfy a necessity to cure the slabs after their manufacture in the ambient conditions a set of experiments were performed on modification of the AAC concrete mix in order to obtain the early strength ( 1 day) in the conditions of their hardening at low temperatures $\left(\mathrm{t}=5-14^{\circ} \mathrm{C}\right)$. For this, a proposal was put forward to present a new activator in the cement composition. 
Table 3 The modified AAC concrete compositions intended for hardening at low temperatures.

\begin{tabular}{|l|c|c|c|}
\hline \multirow{2}{*}{ Concrete ingredients } & \multicolumn{3}{|c|}{ Concrete composition, $\mathrm{kg} / \mathrm{m}^{3}$} \\
\cline { 2 - 4 } & \multicolumn{3}{|c|}{ Marking } \\
\cline { 2 - 4 } & $\mathrm{B}-20-\mathrm{H}(4)$ & $\mathrm{B}-20-\mathrm{H}(2)$ & $\mathrm{B}-20-\mathrm{H}(\mathrm{S})$ \\
\hline Slag & 249.0 & 236.7 & 291.0 \\
\hline OPC & 15.0 & 15.0 & 17.0 \\
\hline Activator 1 & 24.0 & 36.0 & 28.0 \\
\hline Activator 3 & 12.0 & 6.0 & - \\
\hline Activator 2 & - & 12.0 & 14.0 \\
\hline Water reducer 1 & 1.5 & 1.5 & 1.75 \\
\hline Water reducer 2 & 0.45 & 750.0 & 0.5 \\
\hline Fine aggregate & 750.0 & 1150.0 & 1150.0 \\
\hline Coarse aggregate & 1150.0 & 0.389 & 0.38 \\
\hline W/C & 0.41 & & \\
\hline
\end{tabular}

\section{Results and discussion}

The results of visual examination of the manufactured specimens with the compositions shown in Table 1 on the next day suggested that only the concrete mix of the composition B-20-H (4) had good strength for de-shuttering, the rest of the specimens of the other compositions could be de-shuttered only on the second day. The manufactured concrete with the compositions of Table 1 could be classified as a grade $\mathrm{C} 40$ concrete, but with the slump of $18 \mathrm{~cm}$ it could attained a strength which would be enough for de-shuttering only after 4 days. The appearance of the specimens with and without covered with a plastic sheet after de-shuttering in the ambient conditions is shown in Fig. 1.

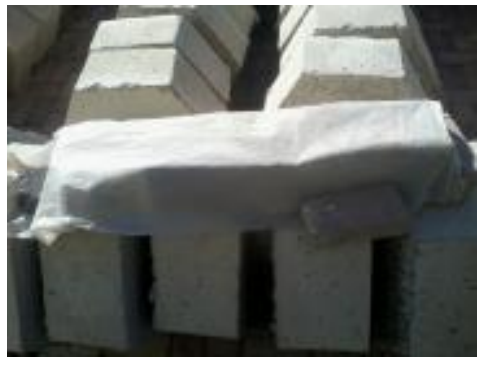

a)

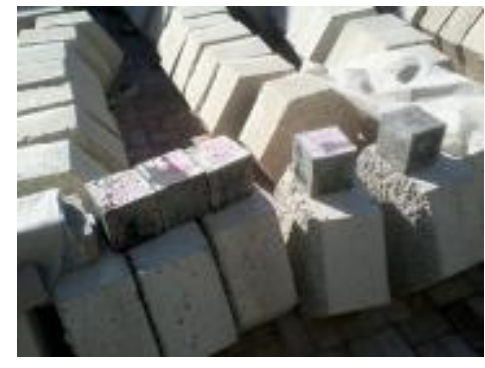

b)

Figure 1 Cure conditions of the AAC concrete specimens: a) - covered; b) - uncovered (open surface)

On the other hand, the ACC concrete specimens, which hardened at $20-30^{\circ} \mathrm{C}$ (Fig. 2a), were characteristic of rather high strength for their de-shuttering after 8-10 hours of hardening and no sign of surface wear.

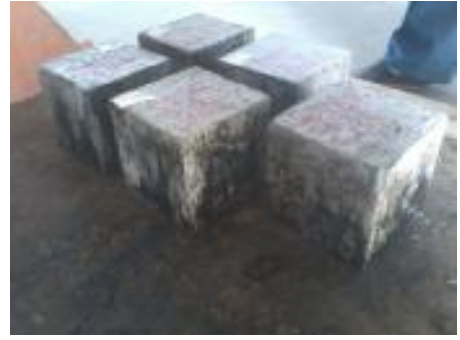

a)

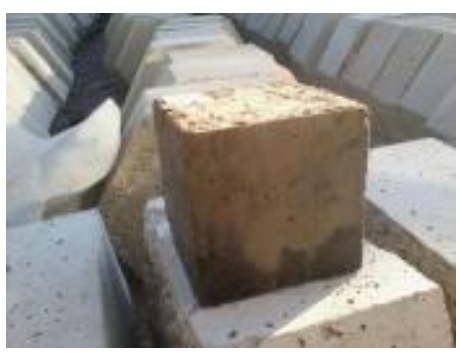

b)

Figure 2. Appearance of the $\mathrm{ACC}$ concrete specimens: a) hardened at $\mathrm{t}=20-30^{\circ} \mathrm{C}$ and $\mathrm{RH}=$ $100 \%$; b) hardened at $\mathrm{t}=6-12^{\circ} \mathrm{C}$ and $\mathrm{RH}=35 \%$. 
A pilot-scale batch, which after manufacture was placed into the chamber for curing at $\mathrm{t}=25-30^{\circ} \mathrm{C}$ and $\mathrm{RH}=100 \%$, on the next day the slabs were de-shuttered. The appearance of the AAC concrete slabs is given in Fig. 3. As seen from Fig. 3, some of the slabs have cavities due not optimal water to cement ratio of the AAC concrete, but the surface of the slabs was strong and did not crumble.
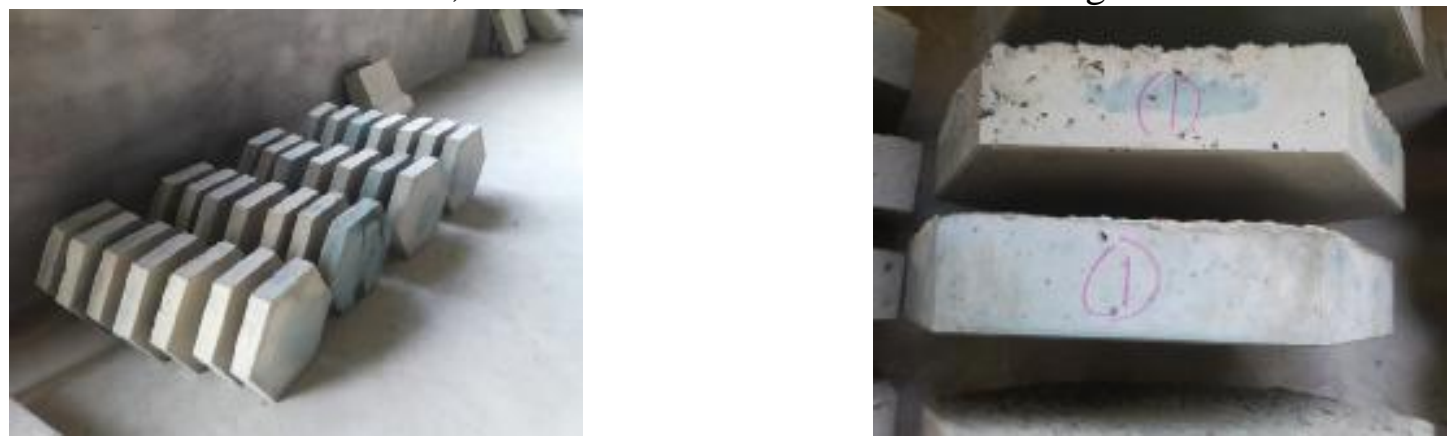

Figure 3 Appearance of the manufactured slabs after hardening at $\mathrm{t}=20-30^{\circ} \mathrm{C}$ and $\mathrm{RH}=100 \%$.

However, after the AAC concrete specimens were allowed to harden in the conditions of the lower temperatures $\left(5-12^{\circ} \mathrm{C}\right)$, the AAC concretes were characteristic of enough strength for de-shuttering only after 2 days. However, the strength of these specimens was very low and these specimens required an additional cure for strength gain, and possibly, the longer time of keeping them under the plastic sheet material. Thus, in the course of this work a necessity to apply the following cure temperatures $\left(20-30^{\circ} \mathrm{C}\right)$ and $\mathrm{RH}=100 \%$ for the AAC concretes which would allow de-shuttering the AAC concrete products from the moulds on the following day and would reduce a duration of keeping the AAC concrete products under the plastic sheet material.

With the composition of Table 2, the experimental results showed that the increase of the content of activators 1 or 2 in the AAC cement would not allow to solve a task of achieving an early strength (1 day) of the AAC concretes in the conditions of their hardening at low temperatures $\left(t=5-14^{\circ} \mathrm{C}\right)$. On the next day these AAC concrete specimens were characteristic of low strength and their de-shuttering was not possible. In the view of the above, in the pilot-scale production of the slabs, their cure should been carried out in the chamber at $\mathrm{t}=25-30^{\circ} \mathrm{C}$ and $\mathrm{RH}=100 \%$.

In order to meet a requirement to cure the slabs after their manufacture in the ambient conditions, a set of experiments were performed on modification of the AAC concrete mix in order to obtain the early strength ( 1 day) in the conditions of their hardening at low temperatures $\left(t=5-14^{\circ} \mathrm{C}\right)$. For this, a proposal was put forward to add activator 3 in the cement composition and to consider a possibility to increase a total content of the alkali activated cement in the AAC concrete without changing the cement composition, as shown in Table 3. Based on the experimental results, the composition B-20-H (4) was chosen to make a pilot production. In manufacture of the slabs the AAC concrete could be easily placed into the moulds. On the next day, the slabs could be easily de-shuttered, and the AAC concrete showed a rather high strength and good appearance (Fig. 4).
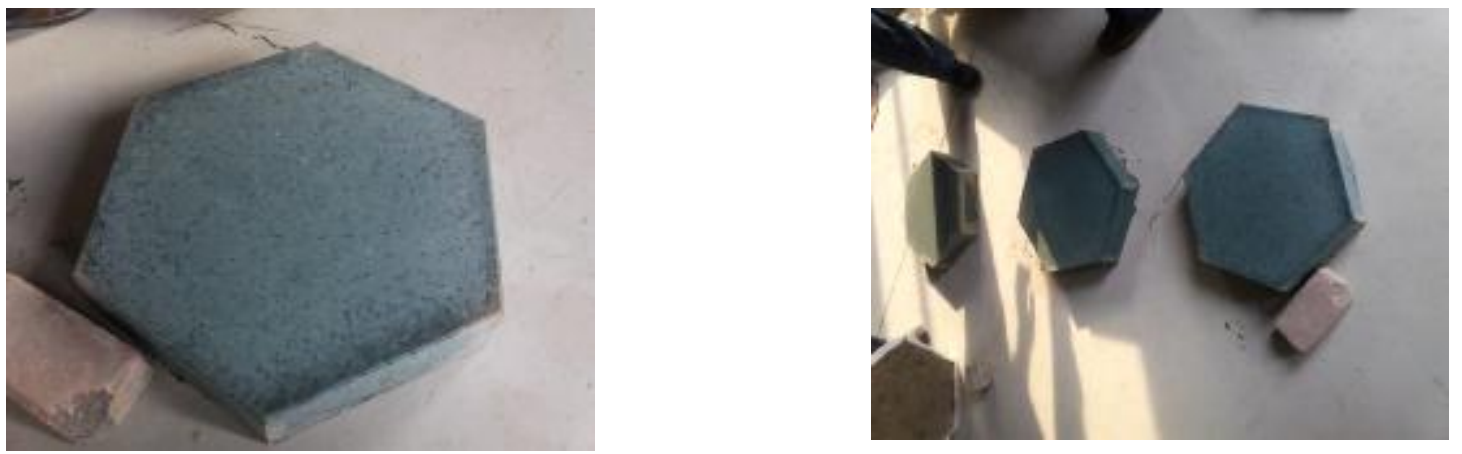

Figure 4 Appearance of the AAC concrete slabs after hardening at low temperatures and de-shuttered on the next day after manufacture. 


\section{Conclusions}

(1) The result of pilot-scale production suggested to reveal general drawbacks as to the concrete cure in ambient conditions, which resulted in over-drying of the slab surface and, hence, determined the increased wear in abrasion of their surfaces and crack formation.

(2) The results of experiments suggested to show an efficiency of curing at $t=20-30^{\circ} \mathrm{C}$. For this, the factory started preparation of a large-size curing chamber with required parameters $\left(\mathrm{t}=20-30^{\circ} \mathrm{C}\right.$ and $\mathrm{RH}=100 \%$ ).

(3)The composition of the modified AAC concrete which is capable to harden and gain early strength after 8-10 hours in the conditions of low temperatures due to substitution of activator 2 for activator 3 .

(4)Three pilot-scale production batches of slabs, two of which have been subjected to curing at $\mathrm{t}=20-30^{\circ} \mathrm{C}$ and one batch, which hardened in the ambient conditions (low temperatures) have been manufactured. This allowed to confirm a possibility and efficiency of two technological solutions/approaches to the manufacture of the concrete products from the alkali activated cements.

\section{Acknowledgements}

This work was financially supported by the "Special funds for innovative and entrepreneurial talents of high level overseas talents in Shenzhen” (KQTD201208, Shenzhen Municipal Science And Technology Innovation Committee).

\section{References}

[1] R. Malinowski, Ancient Mortars and Concretes: Aspect of Their Durability, History of Technology, 7, S9-101 (1982).

[2] R. Malinowski R., A.Slatkine A., M. Ben Yair, Durability of Roman Mortars and Concretes for Hydraulic Structures at Caesarea and Tiberias, Proceed. Int. Symp. on Durability of Concrete, Prague, 1- 14 (1961).

[3] R.Malinowski, Concrete and Mortars in Ancient Aqueducts, Concrete International, 1, 66-67 (1979).

[4] R. Malinowski, Betontechnische Problemlosung bei antiken Wasserbauten, Leichtweiss Institut, Braunschweig, Mitteilungeng, 64, 7-12 (1979).

[5] C.A. Langton, D.M. Roy, Longevity of Borehole and shaft sealing Materials: Characterization of ancient cement-based building materials, Materials Research Society Symposium Proceeding, Pittsburg, 26, 543-549 (1984).

[6] J.Davidovits, Ancient and modern concretes: what is the real difference? Concrete International, 9, 23- 29 (1988).

[7] V.D.Glukhovsky, Ancient, Modern and Future Concretes, Proceed. $2^{\text {nd }}$ Int. Seminar, Gothenburg, Sweden, 53- 62 (1989). 